\title{
Estimating the extent of degradation of ruminant feeds from a description of their gas production profiles observed in vitro: derivation of models and other mathematical considerations
}

\author{
J. France ${ }^{1 *}$, J. Dijkstra ${ }^{2}$, M. S. Dhanoa ${ }^{3}$, S. Lopez ${ }^{4}$ and A. Bannink ${ }^{5}$ \\ ${ }^{1}$ The University of Reading, Department of Agriculture, PO Box 236, Earley Gate, Reading RG6 6AT, UK \\ ${ }^{2}$ Wageningen Institute of Animal Sciences, Animal Nutrition Group, Wageningen Agricultural University, \\ Marijkeweg 40, 6709 PG Wageningen, The Netherlands \\ ${ }^{3}$ Institute of Grassland and Environmental Research, Plas Gogerddan, Aberystwyth, SY23 3EB, UK \\ ${ }^{4}$ Department of Animal Production, University of Leon, 24007 Leon, Spain \\ ${ }^{5}$ Institute for Animal Science and Health (ID-DLO), PO Box 65, 8200 AB Lelystad, The Netherlands
}

(Received 9 June 1998 - Revised 24 May 1999 - Accepted 19 July 1999)

\begin{abstract}
Equations to describe gas production profiles, obtained using manual or automated systems for in vitro fermentation of ruminant feeds, were derived from first principles by considering a simple three-pool scheme. The pools represented were the potentially degradable and undegradable feed fractions, and accumulated gases. The equations derived and investigated mathematically were the generalized Mitscherlich, generalized Michaelis-Menten, Gompertz, and logistic. They were obtained by allowing the fractional rate of degradation to vary with time. The equations permit the extent of ruminal degradation (hence the supply of microbial protein to the duodenum) to be evaluated, thus linking the gas production technique to animal production.
\end{abstract}

Rumen: Gas production: Mathematical models

The development of new gas production methods (Theodorou et al. 1994) and the automation of existing ones (Beuvink et al. 1992) have led to the urgent need for suitable mathematical models to describe and interpret cumulative gas production profiles. These profiles vary in shape from steep diminishing returns to highly sigmoidal, thereby creating a difficulty in the choice of an appropriate model. The slope of the profile tends to be zero in the early stage of fermentation, as there is little or no gas production, giving rise to a lag phase. Thereafter, a steady increase is observed until substrate depletion causes the profile to approach an upper asymptote. Ideally, a function is required which is capable of modelling both a range of shapes with no inflexion point and a range of sigmoidal shapes in which the inflexion point is variable.

Several models, e.g. Mitscherlich, Michaelis-Menten and Gompertz equations, have been proposed for this purpose (Krishnamoorthy et al. 1991; Merry et al. 1991; France et al. 1993; Beuvink \& Kogut, 1993; Blümmel \& Orskov, 1993; Schofield et al. 1994; Groot et al. 1996), sometimes blending empiricism with a more mechanistic view based on a compartmental scheme. However, there appears to be a lack of appreciation of the relationship of the various models to each other and to more general models.
Crucially, the models generally fail to establish the link between gas production in vitro and extent of degradation in the rumen.

The objectives of the present paper are to present a unifying analysis of this area, pointing out compartmental interpretations of some of the candidate models, and to link the gas production technique to animal performance by deriving an expression for the extent of ruminal degradation for each model. The models are presented under the headings of the generalized Mitscherlich, generalized Michaelis-Menten, and standard growth functions. Mathematically, the approach adopted is to provide a diagram relevant to each model, translate the diagram to mathematics, solve the mathematics, and illustrate the resultant algebraic solution. The models derived herein have been evaluated in a companion paper by fitting them to gas production profiles obtained using a diverse range of ruminant feeds (Dhanoa et al. 2000).

\section{Generalized Mitscherlich}

Although aspects of the derivation presented in this section have been reported previously (France et al. 1993), the

* Corresponding author: Professor J. France, fax +44 (0)118 935 2421, email j.france@reading.ac.uk 
complete analysis is given here $a b$ initio in an attempt to establish a framework for considering the other models.

Consider an amount (g DM) of a particular feed or feed component, such as plant leaf, plant stem or total organic matter (OM), placed in a culture bottle at time zero, and let the component comprise a degradable fraction $S$ and an undegradable fraction U. Degradation occurs at a fractional rate $\mu(/ \mathrm{h})$ and a discrete lag $\mathrm{T}(\mathrm{h})$ is assumed to occur before degradation commences. The three-pool scheme is shown in Fig. 1. The dynamic behaviour of the two feed-component fractions (both pools in $\mathrm{g}$ ) is described by the differential equations:

$$
\begin{aligned}
\mathrm{dS} / \mathrm{dt} & =0,0 \leqslant \mathrm{t}<\mathrm{T} \\
& =-\mu \mathrm{S}, \mathrm{t} \geqslant \mathrm{T},
\end{aligned}
$$

and

$$
\mathrm{dU} / \mathrm{dt}=0, \mathrm{t} \geqslant 0 .
$$

In this case the fractional rate of degradation $\mu$ is postulated to vary with time $\mathrm{t}$ as follows:

$$
\mu=\mathrm{b}+\mathrm{c} /(2 \sqrt{ } \mathrm{t}), \mathrm{t} \geqslant \mathrm{T},
$$

where $\mathrm{b}(/ \mathrm{h})$ and $\mathrm{c}\left(\mathrm{h}^{-1 / 2}\right)$ are constants. The conditions $\mathrm{b} \geqslant 0$, $c \geqslant-2 b \sqrt{ } T$ have to be satisfied as $\mu$ cannot be negative. Equation 3 permits the fractional degradation rate to remain constant, or to decline or increase asymptotically with time. It is possible to provide a tentative interpretation of equation 3 (France et al. 1996). Many diffusion processes exhibit a square root time dependence. For instance, the distance

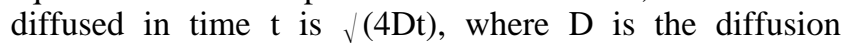
constant. The diffusion of a growth activator into a growthproducing region, after a lag time, (and by analogy the degradation by microbial enzymes of plant cell-wall material in the rumen) could lead to an activation equation similar to 3 .

On substituting for $\mu$ using equation 3 and integrating, equations 1 and 2 yield:

$$
\begin{aligned}
\mathrm{S} & =\mathrm{S}_{0}, 0 \leqslant \mathrm{t}<\mathrm{T} \\
& =\mathrm{S}_{0} \mathrm{e}^{-[\mathrm{b}(\mathrm{t}-\mathrm{T})+\mathrm{c}(\sqrt{ } \mathrm{t}-\sqrt{ } \mathrm{T})]}, \mathrm{t} \geqslant \mathrm{T},
\end{aligned}
$$

and

$$
\mathrm{U}=\mathrm{U}_{0}, \mathrm{t} \geqslant 0,
$$

where $\mathrm{S}_{0}$ and $\mathrm{U}_{0}$ are the zero-time quantities of the degradable and undegradable fractions of the feed component respectively.

If the rate of gas production in the culture bottle is assumed to be directly proportional to the rate of
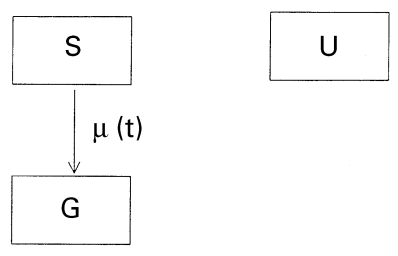

Fig. 1. The three-pool scheme for feed degradation. The pools are: degradable substrate $\mathrm{S}(\mathrm{g})$, undegradable substrate $\mathrm{U}(\mathrm{g})$ and accumulated gases $\mathrm{G}(\mathrm{ml})$. The fractional degradation rate $\mu(/ \mathrm{h})$ varies over time and a discrete lag is assumed to occur before degradation commences. degradation of feed component, then:

$$
\mathrm{dG} / \mathrm{dt}=-\mathrm{YdS} / \mathrm{dt}
$$

where $\mathrm{G}(\mathrm{ml})$ denotes total gas accumulation to time $\mathrm{t}$ and $\mathrm{Y}$ $(\mathrm{ml} / \mathrm{g}$ degradable DM) is a constant yield factor. The negative sign is introduced into equation 6 because $G$ and $S$ vary in opposite senses, in that $G$ accumulates as $S$ depletes. Using equation $1 \mathrm{~b}$ to substitute for $\mathrm{dS} / \mathrm{dt}$ in equation 6 then differentiating leads to:

$$
\mathrm{d}^{2} \mathrm{G} / \mathrm{dt}^{2}=\mathrm{YS}\left(\mathrm{d} \mu / \mathrm{dt}-\mu^{2}\right), \mathrm{t} \geqslant \mathrm{T} .
$$

A point of inflexion exists when $\mathrm{d}^{2} \mathrm{G} / \mathrm{dt}^{2}$ equals zero, i.e.

$$
\mathrm{d} \mu / \mathrm{dt}=\mu^{2} \text {. }
$$

Total gas accumulation to time $\mathrm{t}$ is given by integrating equation 6 :

$$
\mathrm{G}=\mathrm{Y}\left(\mathrm{S}_{0}-\mathrm{S}\right) \text {. }
$$

Using equation $4 \mathrm{~b}$ to substitute for $\mathrm{S}$ gives a generalization of the Mitscherlich:

$$
\mathrm{G}=\mathrm{YS}_{0}\left\{1-\mathrm{e}^{-[\mathrm{b}(\mathrm{t}-\mathrm{T})+\mathrm{c}(\sqrt{ } \mathrm{t}-\sqrt{ } \mathrm{T})]}\right\}, \mathrm{t} \geqslant \mathrm{T} .
$$

A range of values of $\mathrm{c}$ is considered in Fig. 2 which shows the general behaviour of this cumulative gas production equation, whose form can give rise to a variable inflexion point (France et al. 1996).

A point of inflexion exists if:

$$
-c /\left(4 \sqrt{ } T^{3}\right) \geqslant[b+c /(2 \sqrt{ })]^{2}
$$

The condition is obtained from equation 8 using equation 3 for $\mu$. This leads to:

$$
\sqrt{ }(-\mathrm{c}) \geqslant\left\{\sqrt{ }[1 /(2 \sqrt{ } \mathrm{T})+4 \mathrm{~b} / \mathrm{T}]-1 /\left(\sqrt{ } 2 \mathrm{~T}^{1 / 4}\right)\right\} / \sqrt{ } 2,
$$

which, for the parameter values used in Fig. 2, gives $-0.6 \leqslant c \leqslant-0.29$ for an inflexion point. Thus, in Fig. 2, $-0.6 \leqslant c \leqslant-0.29$ gives sigmoidal accumulation, whereas $-0.29<\mathrm{c}<\infty$ gives non-sigmoidal accumulation. The values -0.6 and -0.29 are not invariant, but vary with the choice of the other parameters. The inflexion points for the curves shown in Fig. 2 occur at 22.8 and $23.7 \mathrm{~h}$ for $\mathrm{c}$ equals -0.6 and $-0.4 / \mathrm{h}^{-1 / 2}$ respectively. Equation 12 shows there is no inflexion point for positive $\mathrm{c}$.

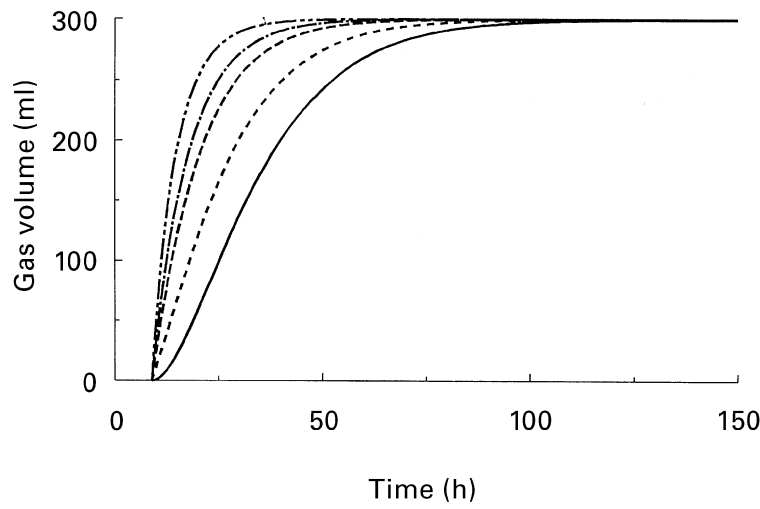

Fig. 2. The range of behaviour of the generalized Mitscherlich model with $Y=500 \mathrm{ml} / \mathrm{g}, S_{0}=0.6 \mathrm{~g}, \mathrm{~b}=0.1 / \mathrm{h}$ and $T=9 \mathrm{~h}$. The units of $\mathrm{c}$ are $/ \mathrm{h}^{-1 / 2} .(-), \mathrm{c}=-0.60 ;(---), \mathrm{c}=-0.40 ;(---), \mathrm{c}=-0.10$; $(-\cdot-\cdot), c=0.10 ;(-\cdot-), c=0.50$. 
We define $t_{p}(h)$ as the time (from incubation) needed for proportion $\mathrm{p}$ of the degradable fraction $\mathrm{S}_{0}$ to disappear (i.e. be degraded). Equation $4 \mathrm{~b}$ can be re-arranged to give:

$$
\mathrm{bt}+\mathrm{c} \sqrt{ } \mathrm{t}-\left[\mathrm{bT}+\mathrm{c} \sqrt{\mathrm{T}}-\ln \left(\mathrm{S} / \mathrm{S}_{0}\right)\right]=0 .
$$

The p-time calculation is obtained from the root of this equation and given by:

$$
\mathrm{t}_{\mathrm{p}}=\left[\left(-\mathrm{c} / 2+\sqrt{ }\left\{\mathrm{c}^{2} / 4+\mathrm{b}[\mathrm{bT}+\mathrm{c} / \mathrm{T}-\ln (1-\mathrm{p})]\right\}\right) / \mathrm{b}\right]^{2}
$$

for positive $b$ (the other root leads to biologically inadmissible $p$-time values). The value of $t_{p}$ will always exceed the lag T. Now p may have any value in the range 0-100 using a percentage scale. For comparison of different feeds based on gas pool size, a value consistent with the recording period is desirable. The time, $\mathrm{t}_{95}$, taken for gas accumulation to reach $95 \%$ of its asymptotic value may provide such an index (say $\mathrm{G}_{95}$ ) that can be used to rank different substrates. Another useful value is $t_{50}$, the half-life of the degradable fraction. The half-lives for the curves illustrated in Fig. 2 are 31.7, 23.2, $17 \cdot 1,15 \cdot 1$ and $12 \cdot 9 \mathrm{~h}$ for $\mathrm{c}$ equal to $-0 \cdot 6,-0 \cdot 4,-0 \cdot 1$, $0 \cdot 1$ and $0 \cdot 5 / \mathrm{h}^{-1 / 2}$ respectively. Some workers may prefer to use other values, e.g. $t_{25}, t_{75}$ or the difference $t_{75}-t_{25}$.

In the rumen proper, feed is subjected to passage and thus the dynamics of the two feed-component fractions obey the following differential equations:

$$
\begin{aligned}
\mathrm{dS} / \mathrm{dt} & =-\mathrm{kS}, 0 \leqslant \mathrm{t}<\mathrm{T} \\
& =-(\mu+\mathrm{k}) \mathrm{S}, \mathrm{t} \geqslant \mathrm{T},
\end{aligned}
$$

and

$$
\mathrm{dU} / \mathrm{dt}=-\mathrm{kU}, \mathrm{t} \geqslant 0
$$

where $\mathrm{k}(/ \mathrm{h})$ is the passage rate constant. On using equation 3 to substitute for $\mu$, their solution is:

$$
\begin{aligned}
\mathrm{S} & =\mathrm{S}_{0} \mathrm{e}^{-\mathrm{kt}}, 0 \leqslant \mathrm{t}<\mathrm{T} \\
& =\mathrm{S}_{0} \mathrm{e}^{-[(\mathrm{b}+\mathrm{k})(\mathrm{t}-\mathrm{T})+\mathrm{c}(\sqrt{ } \mathrm{t}-\sqrt{ } \mathrm{T})+\mathrm{kT}]}, \mathrm{t} \geqslant \mathrm{T},
\end{aligned}
$$

and

$$
\mathrm{U}=\mathrm{U}_{0} \mathrm{e}^{-\mathrm{kt}}, \mathrm{t} \geqslant 0 .
$$

The extent of degradation in the rumen is given by the equation:

$$
\mathrm{E}=\int_{\mathrm{T}}^{\infty} \mu \mathrm{Sdt} /\left(\mathrm{S}_{0}+\mathrm{U}_{0}\right) .
$$

The instantaneous rate of degradation in the rumen at time $\mathrm{t}$ $(>\mathrm{T})$ is $\mu \mathrm{S}$, so the total amount degraded will be the integral over all this time, and the extent of degradation is defined as the total amount degraded divided by the amount entering, which gives equation 19 . Using equations 3 and $17 \mathrm{~b}$ to substitute for $\mu$ and $\mathrm{S}$ respectively in equation 19 , then:

$$
\mathrm{E}=\mathrm{S}_{0} \mathrm{I} /\left(\mathrm{S}_{0}+\mathrm{U}_{0}\right),
$$

where:

$$
\mathrm{I}=\int_{\mathrm{T}}^{\infty}[\mathrm{b}+\mathrm{c} /(2 \sqrt{ } \mathrm{t})] \mathrm{e}^{-[(\mathrm{b}+\mathrm{k})(\mathrm{t}-\mathrm{T})+\mathrm{c}(\sqrt{ } \mathrm{t}-\sqrt{ } \mathrm{T})+\mathrm{kT}]} \mathrm{dt} .
$$

The integral I is non-analytical (i.e. cannot be integrated to yield an algebraic equation) and has to be evaluated numerically. Obviously, E and I are dimensionless.
Thus, values of $\mathrm{S}_{0}$ and $\mathrm{U}_{0}$ (obtained from the gas production technique by measuring the zero-time degradable and undegradable fractions), and estimates of b, c, and $\mathrm{T}$ (obtained by fitting equation 10 to the cumulative gas production data), used in conjunction with an estimate of the rate of passage $\mathrm{k}$ (obtained using digesta-flow markers and either faecal or ruminal sampling), permit evaluation of the extent of ruminal degradation of a feed or feed component by applying equations 20 and 21 (Dhanoa et al. 2000). The yield factor $\mathrm{Y}$ can also be obtained from fitting equation 10 given $\mathrm{S}_{0}$.

\section{Special case}

If the fractional degradation rate $\mu$ is constant then parameter $\mathrm{c}$ is zero, $\mu$ equals $\mathrm{b}$, and the gas production equation becomes:

$$
\mathrm{G}=\mathrm{YS}_{0}\left[1-\mathrm{e}^{-\mu(\mathrm{t}-\mathrm{T})}\right], \mathrm{t} \geqslant \mathrm{T} .
$$

Equation 22 is an example of the well-known Mitscherlich function which has enjoyed widespread usage amongst ruminant nutritionists in the analysis of in situ digestion data (Ørskov \& McDonald, 1979). A range of values for $\mu$ is shown in Fig. 3 which illustrates the general behaviour of this equation. The rate of accumulation decreases continually and there is no point of inflexion. This can be seen from the second differential (equation 7), which can only be zero when $\mathrm{S}$ is exhausted as $\mu$ is a positive constant.

For this special case $(c=0, \mu=b)$, the integral I (equation 21 ) is analytical. Integrating equation 21 gives:

$$
\mathrm{E}=\mathrm{S}_{0} \mathrm{e}^{-\mathrm{kT}} \mu /\left[(\mu+\mathrm{k})\left(\mathrm{S}_{0}+\mathrm{U}_{0}\right)\right] .
$$

Thus the extent of degradation in the rumen can now be evaluated using a simple algebraic expression.

\section{Generalized Michaelis-Menten}

The scheme is shown in Fig. 1. In this case the fractional degradation rate $\mu$ varies with time $\mathrm{t}$ as:

$$
\mu=\mathrm{c}(\mathrm{t}-\mathrm{T})^{\mathrm{c}-1} /\left[(\mathrm{t}-\mathrm{T})^{\mathrm{c}}+\mathrm{K}^{\mathrm{c}}\right], \mathrm{t} \geqslant \mathrm{T},
$$

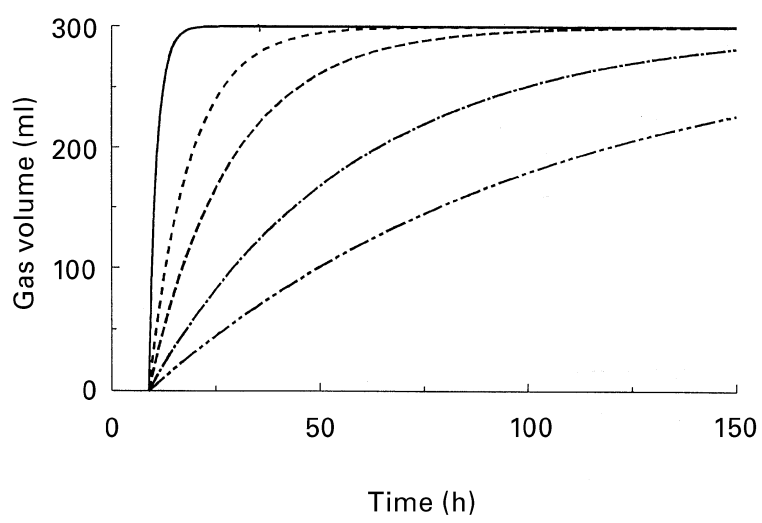

Fig. 3. The range of behaviour of the simple Mitscherlich model with $\mathrm{Y}=500 \mathrm{ml} / \mathrm{g}, \mathrm{S}_{0}=0.6 \mathrm{~g}$, and $\mathrm{T}=9 \mathrm{~h}$. The units of $\mu$ are $/ \mathrm{h}$. (—), $\mu=0.50$; (---), $\mu=0.10$; (-- ),$\mu=0.05$; (-.-.), $\mu=0.02$; $(---), \mu=0.01$. 
where $\mathrm{c}$ (dimensionless) and $\mathrm{K}(\mathrm{h})$ are positive constants. The conditions $\mathrm{c}>0, \mathrm{~K}>0$ have to be satisfied as $\mu$ cannot be negative. $K$ is the time after lag time $T$ when half the amount of substrate is degraded (equation 25b). Equation 24 permits the fractional degradation rate to decrease continually $(c \leqslant 1)$, or to increase to reach a maximum and then decrease again $(c>1)$.

The dynamics of the two feed-component fractions are given by equations 1 and 2 . On substituting for $\mu$ using equation 24 and integrating, equations 1 and 2 now yield:

$$
\begin{aligned}
\mathrm{S} & =\mathrm{S}_{0}, 0 \leqslant \mathrm{t}<\mathrm{T} \\
& =\mathrm{S}_{0} \mathrm{~K}^{\mathrm{c}} /\left[(\mathrm{t}-\mathrm{T})^{\mathrm{c}}+\mathrm{K}^{\mathrm{c}}\right], \mathrm{t} \geqslant \mathrm{T},
\end{aligned}
$$

and

$$
\mathrm{U}=\mathrm{U}_{0}, \mathrm{t} \geqslant 0 \text {. }
$$

Equation 9 applies, assuming the rate of gas production is directly proportional to the rate of degradation of feed component, giving:

$$
\mathrm{G}=\mathrm{YS}_{0}(\mathrm{t}-\mathrm{T})^{\mathrm{c}} /\left[(\mathrm{t}-\mathrm{T})^{\mathrm{c}}+\mathrm{K}^{\mathrm{c}}\right], \mathrm{t} \geqslant \mathrm{T} .
$$

A range of values of $\mathrm{c}$ is illustrated in Fig. 4 that shows the general behaviour of this equation, which has a variable point of inflexion when $\mathrm{c}>1$.

The point of inflexion satisfies equation 8 which yields the condition:

$$
(\mathrm{c}-1) \mathrm{K}^{\mathrm{c}}-(\mathrm{c}+1)(\mathrm{t}-\mathrm{T})^{\mathrm{c}}=0 .
$$

If the point of inflexion occurs at time $t^{*}(>T)$, then $t^{*}$ is given by:

$$
\mathrm{t}^{*}=\mathrm{T}+\mathrm{K}[(\mathrm{c}-1) /(\mathrm{c}+1)]^{1 / \mathrm{c}}, \mathrm{c}>1 .
$$

The inflexion points for the curves shown in Fig. 4 occur at $23 \cdot 4,32 \cdot 1$ and $33 \cdot 5 \mathrm{~h}$ for c equals 2,5 and 10 respectively. The time from incubation needed for proportion $\mathrm{p}$ of $\mathrm{S}_{0}$ to disappear is found using equation $25 \mathrm{~b}$ and is:

$$
\mathrm{t}_{\mathrm{p}}=\mathrm{T}+\mathrm{K}[\mathrm{p} /(1-\mathrm{p})]^{1 / \mathrm{c}} \text {. }
$$

The half-lives for the curves in Fig. 4 are all 34.0 h.

In the rumen, where feed is also subject to passage, the two feed-component fractions obey differential equations

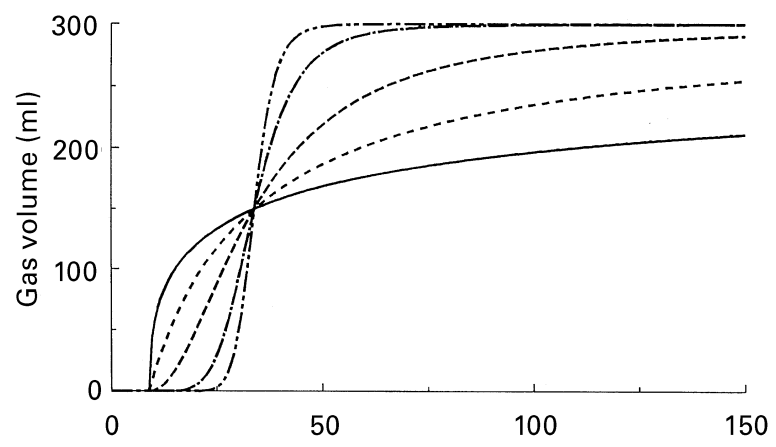

Time (h)

Fig. 4. The range of behaviour of the generalized MichaelisMenten model with $Y=500 \mathrm{ml} / \mathrm{g}, S_{0}=0.6 \mathrm{~g}, K=25 \mathrm{~h}$ and $\mathrm{T}=9 \mathrm{~h}$. The parameter $c$ is dimensionless. $(-), c=0.5 ;(--), c=1$; $(---), c=2 ;(-\cdot-), c=5 ;(---), c=10$.
15 and 16. Using equation 24 to substitute for $\mu$, their solution is:

$$
\begin{aligned}
\mathrm{S} & =\mathrm{S}_{0} \mathrm{e}^{-\mathrm{kt}}, 0 \leqslant \mathrm{t}<\mathrm{T} \\
& =\mathrm{S}_{0} \mathrm{~K}^{\mathrm{c}} \mathrm{e}^{-\mathrm{kt}} /\left[(\mathrm{t}-\mathrm{T})^{\mathrm{c}}+\mathrm{K}^{\mathrm{c}}\right], \mathrm{t} \geqslant \mathrm{T},
\end{aligned}
$$

and

$$
\mathrm{U}=\mathrm{U}_{0} \mathrm{e}^{-\mathrm{kt}}, \mathrm{t} \geqslant 0 .
$$

The extent of degradation in the rumen is given by equations 19 and 20 with:

$$
\mathrm{I}=\mathrm{cK}^{\mathrm{c}} \int_{\mathrm{T}}^{\infty}\left\{(\mathrm{t}-\mathrm{T})^{\mathrm{c}-1} \mathrm{e}^{-\mathrm{kt}} /\left[(\mathrm{t}-\mathrm{T})^{\mathrm{c}}+\mathrm{K}^{\mathrm{c}}\right]^{2}\right\} \mathrm{dt} .
$$

Again, the integral $I$ is non-analytical and has to be evaluated numerically.

\section{Special case}

In this case the parameter $c$ equals 1 so the fractional degradation rate varies with time $t$ as follows:

$$
\mu=1 /(\mathrm{t}-\mathrm{T}+\mathrm{K}), \mathrm{t} \geqslant \mathrm{T},
$$

where $K(>0)$ is the inverse of $\mu_{\max }$. The gas production equation becomes:

$$
\mathrm{G}=\mathrm{YS}_{0}(\mathrm{t}-\mathrm{T}) /(\mathrm{t}-\mathrm{T}+\mathrm{K}), \mathrm{t} \geqslant \mathrm{T} .
$$

Equation 35 is a rectangular hyperbola and, with $\mathrm{T}$ equals zero, is in the form of the well-known Michaelis-Menten equation of enzyme kinetics. A range of values of $\mathrm{K}$ is shown in Fig. 5 which illustrates the general behaviour of this equation. The rate of accumulation decreases continually and there is no point of inflexion. This can be seen from the second differential $\mathrm{d}^{2} \mathrm{G} / \mathrm{dt}^{2}$ which is only zero for $\mathrm{t} \rightarrow \infty$.

The extent of degradation in the rumen is given by equations 19 and 20 with, in this case:

$$
\mathrm{I}=\mathrm{K} \int_{\mathrm{T}}^{\infty}\left[\mathrm{e}^{-\mathrm{kt}} /(\mathrm{t}-\mathrm{T}+\mathrm{K})^{2}\right] \mathrm{dt} .
$$

This integral is also non-analytical and has to be evaluated numerically.

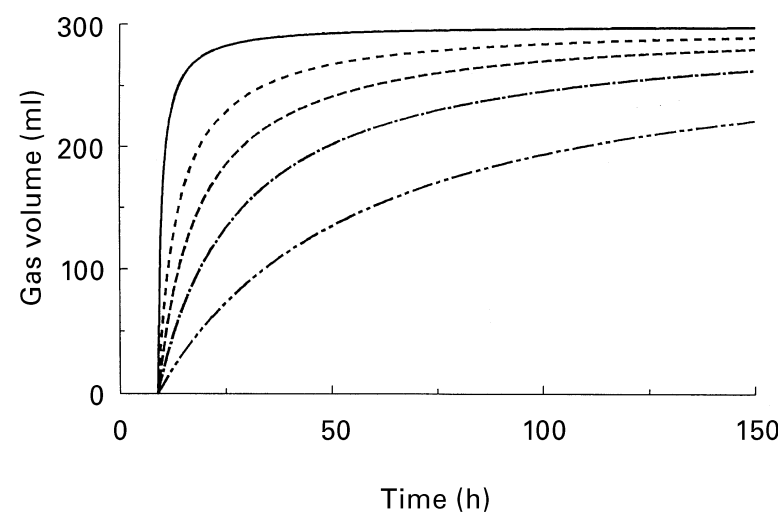

Fig. 5. The range of behaviour of the simple Michaelis-Menten model with $Y=500 \mathrm{ml} / \mathrm{g}, S_{0}=0.6 \mathrm{~g}$ and $T=9 \mathrm{~h}$. The units of $\mathrm{K}$ are $\mathrm{h}$. $(-), \mathrm{K}=1 ;(---), \mathrm{K}=5 ;(---), \mathrm{K}=10 ;(-\cdot-), \mathrm{K}=20 ;(-\cdots-)$, $\mathrm{K}=50$. 


\section{Standard growth functions}

Gompertz

The scheme is shown in Fig. 1. In this case the fractional degradation rate $\mu$ varies with time $\mathrm{t}$ as:

$$
\mu=b e^{\mathrm{c}(\mathrm{t}-\mathrm{T})}, \mathrm{t} \geqslant \mathrm{T},
$$

where $\mathrm{b}$ and $\mathrm{c}$ (both $/ \mathrm{h}$ ) are constants. The restriction $\mathrm{b}>0$ has to be satisfied as $\mu$ cannot be negative and, as explained after equation $38 \mathrm{~b}$, the restriction $\mathrm{c} \geqslant 0$ also has to be satisfied. Equation 37 permits the fractional degradation rate to remain constant or increase exponentially with time.

Equations 1 and 2 give the dynamics of the two feedcomponent fractions. On substituting for $\mu$ using equation 37 and integrating, these yield:

$$
\begin{aligned}
\mathrm{S} & =\mathrm{S}_{0}, 0 \leqslant \mathrm{t}<\mathrm{T} \\
& =\mathrm{S}_{0} \exp \left[-\mathrm{b}\left(\mathrm{e}^{\mathrm{c}(\mathrm{t}-\mathrm{T})}-1\right) / \mathrm{c}\right], \mathrm{t} \geqslant \mathrm{T},
\end{aligned}
$$

and

$$
\mathrm{U}=\mathrm{U}_{0}, \mathrm{t} \geqslant 0 .
$$

It is evident from an inspection of equation $38 \mathrm{~b}$ that $\mathrm{c}(\geqslant 0)$ cannot be negative, because $\mathrm{S}$ must be zero at infinite time. Equation 9 applies, assuming direct proportionality between the rate of gas production and the rate of degradation of feed, giving:

$$
\mathrm{G}=\mathrm{YS}_{0}\left\{1-\exp \left[-\mathrm{b}\left(\mathrm{e}^{\mathrm{c}(\mathrm{t}-\mathrm{T})}-1\right) / \mathrm{c}\right]\right\}, \mathrm{t} \geqslant \mathrm{T} .
$$

The behaviour of this cumulative gas equation is illustrated in Fig. 6 using a range of values for c.

A variable point of inflexion exists, provided $\mathrm{c}$ is greater than $b$, and occurs at time:

$$
\mathrm{t}^{*}=\mathrm{T}+\mathrm{c}^{-1} \ln (\mathrm{c} / \mathrm{b}) \text {. }
$$

The time $\mathrm{t}^{*}(\mathrm{~h})$ is determined using equation 8 , and at this time $\mu$ equals $\mathrm{c}$. The $\mathrm{t}^{*}$ values for the curves illustrated in Fig. 6 are $41 \cdot 2,32 \cdot 0,24 \cdot 0$ and $18 \cdot 2 \mathrm{~h}$ for c equals $0 \cdot 05,0 \cdot 10$, 0.20 and $0.40 / \mathrm{h}$ respectively. The time $\mathrm{t}_{\mathrm{p}}$, that is needed for proportion $\mathrm{p}$ of the degradable fraction $\mathrm{S}_{0}$ to disappear, is found using equation $38 \mathrm{~b}$ which gives:

$$
\mathrm{t}_{\mathrm{p}}=\mathrm{T}+\mathrm{c}^{-1} \ln \{[\mathrm{b}-\mathrm{cln}(1-\mathrm{p})] / \mathrm{b}\} .
$$

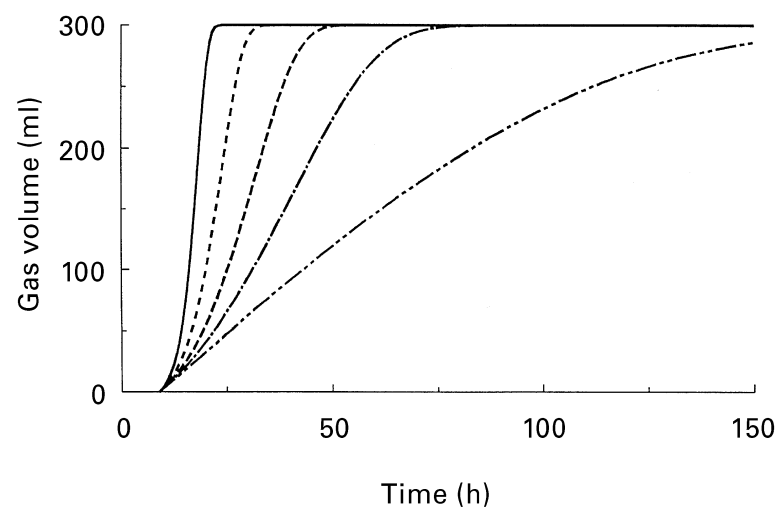

Fig. 6. The general behaviour of the Gompertz model with $Y=$ $500 \mathrm{ml} / \mathrm{g}, S_{0}=0.6 \mathrm{~g}, \mathrm{~b}=0.01 / \mathrm{h}$ and $T=9 \mathrm{~h}$. The units of $\mathrm{c}$ are $/ \mathrm{h}$. $(-), c=0.40 ;(---), c=0.20 ;(---), c=0.10 ;(-\cdot-), c=0.05$; $(---), c=0.01$.
The $\mathrm{t}_{50}$ values for the curves in Fig. 6 are 61.7, 38.9, 29.7, 22.5 and $17.4 \mathrm{~h}$ for c equals $0 \cdot 01,0 \cdot 05,0 \cdot 10,0.20$ and $0.40 / \mathrm{h}$ respectively.

In the rumen, where feed is also subject to passage, the two feed-component fractions obey differential equations 15 and 16. Using equation 37 to substitute for $\mu$, their solution is:

$$
\begin{aligned}
\mathrm{S} & =\mathrm{S}_{0} \mathrm{e}^{-\mathrm{kt}}, 0 \leqslant \mathrm{t}<\mathrm{T} \\
& =\mathrm{S}_{0} \exp \left[-\mathrm{b}\left(\mathrm{e}^{\mathrm{c}(\mathrm{t}-\mathrm{T})}-1\right) / \mathrm{c}-\mathrm{kt}\right], \mathrm{t} \geqslant \mathrm{T},
\end{aligned}
$$

and

$$
\mathrm{U}=\mathrm{U}_{0} \mathrm{e}^{-\mathrm{kt}}, \mathrm{t} \geqslant 0 .
$$

The expressions for extent of ruminal degradation are equations 19 and 20 with:

$$
\mathrm{I}=\mathrm{b} \int_{\mathrm{T}}^{\infty} \exp \left[-\mathrm{b}\left(\mathrm{e}^{\mathrm{c}(\mathrm{t}-\mathrm{T})}-1\right) / \mathrm{c}+(\mathrm{c}-\mathrm{k}) \mathrm{t}-\mathrm{cT}\right] \mathrm{dt} .
$$

This integral is also non-analytical and has to be evaluated numerically.

\section{Logistic}

Again, the scheme is shown in Fig. 1. In this case, the fractional degradation rate $\mu$ varies with substrate $\mathrm{S}$ rather than explicitly with time:

$$
\mu=\mathrm{b}(\mathrm{K}-\mathrm{S}), \mathrm{t} \geqslant \mathrm{T},
$$

where $\mathrm{b}>0(\mathrm{~g} \mathrm{DM} / \mathrm{h})$ and $\mathrm{K} \geqslant \mathrm{S}_{0}(\mathrm{~g} D \mathrm{DM})$ are constants. The term $(\mathrm{K}-\mathrm{S})$ can be interpreted as a temporal indicator of microbial activity per unit of feed.

The dynamics of the two feed-component fractions are once again given by equations 1 and 2 . On substituting for $\mu$ using equation 46 and integrating, these equations now yield:

$$
\begin{aligned}
\mathrm{S} & =\mathrm{S}_{0}, 0 \leqslant \mathrm{t}<\mathrm{T} \\
& =\mathrm{KS}_{0} /\left[\mathrm{S}_{0}+\left(\mathrm{K}-\mathrm{S}_{0}\right) \mathrm{e}^{\mathrm{bK}(\mathrm{t}-\mathrm{T})}\right], \mathrm{t} \geqslant \mathrm{T},
\end{aligned}
$$

and

$$
\mathrm{U}=\mathrm{U}_{0}, \mathrm{t} \geqslant 0 .
$$

Equation 9 applies, assuming the rate of gas production is directly proportional to the rate of degradation of feed component, giving:

$$
\begin{aligned}
\mathrm{G}= & \mathrm{YS}_{0}\left\{\left(1-\mathrm{e}^{-\mathrm{bK}(\mathrm{t}-\mathrm{T})}\right)\right. \\
& \left.\div\left(1+\left[\mathrm{S}_{0} /\left(\mathrm{K}-\mathrm{S}_{0}\right)\right] \mathrm{e}^{-\mathrm{bK}(\mathrm{t}-\mathrm{T})}\right)\right\}, \mathrm{t} \geqslant \mathrm{T} .
\end{aligned}
$$

The behaviour of this gas equation is illustrated in Fig. 7 using a range of values for $b$.

Provided $\mathrm{K}$ is less than $2 \mathrm{~S}_{0}$, a variable point of inflexion occurs when $S$ falls to $K / 2$, i.e. at time:

$$
\mathrm{t}^{*}=\mathrm{T}+(\mathrm{bK})^{-1} \ln \left[\mathrm{S}_{0} /\left(\mathrm{K}-\mathrm{S}_{0}\right)\right] .
$$

The inflexion point occurring at $\mathrm{S}$ equals $\mathrm{K} / 2$ can be ascertained from equation 8 . The $t^{*}$ values for the curves shown in Fig. 7 are 60.2, 34.6, 26.1, $19 \cdot 2$ and $14 \cdot 1 \mathrm{~h}$ for $\mathrm{b}$ equals $0.05,0 \cdot 10,0 \cdot 15,0 \cdot 25$ and $0.50 \mathrm{~g} \mathrm{DM} / \mathrm{h}$ respectively. The time needed for proportion $\mathrm{p}$ of the degradable fraction 


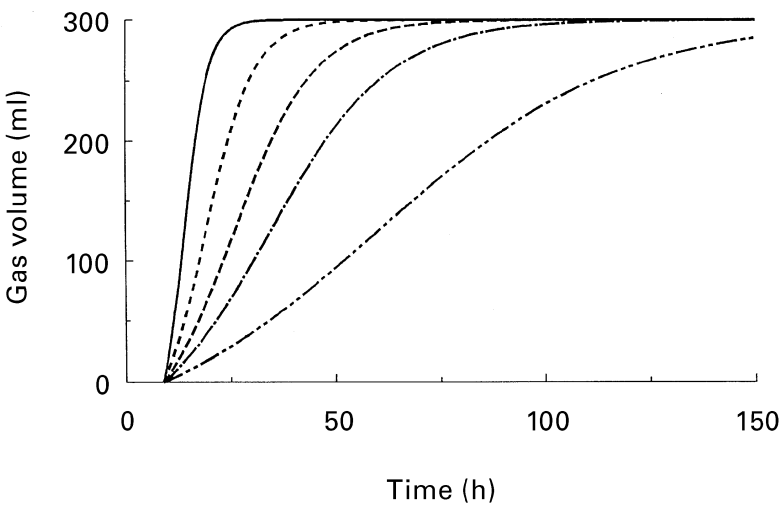

Fig. 7. The general behaviour of the logistic model with $Y=$ $500 \mathrm{ml} / \mathrm{g}, S_{0}=0.6 \mathrm{~g}, K=0.07 \mathrm{~g}$ and $T=9 \mathrm{~h}$. The units of $\mathrm{b}$ are $\mathrm{g} / \mathrm{h}$. $(-), b=0.50 ;(---), b=0.25 ;(---), b=0.15 ;(-\cdot-), b=0.10$; $(---), b=0.05$.

$\mathrm{S}_{0}$ to disappear, $\mathrm{t}_{\mathrm{p}}$, is found from equation $47 \mathrm{~b}$ :

$$
\mathrm{t}_{\mathrm{p}}=\mathrm{T}+(\mathrm{bK})^{-1} \ln \left\{\left[\mathrm{K} /(1-\mathrm{p})-\mathrm{S}_{0}\right] /\left(\mathrm{K}-\mathrm{S}_{0}\right)\right\} .
$$

The $t_{50}$ values for the curves shown in Fig. 7 are 68.4, 38.7, $28 \cdot 8,20 \cdot 9$ and $14.9 \mathrm{~h}$ for b equals $0 \cdot 05,0 \cdot 10,0 \cdot 15,0 \cdot 25$ and $0.50 \mathrm{~g} \mathrm{DM} / \mathrm{h}$ respectively.

In the rumen, the two feed-component fractions obey differential equations 15 and 16 . Using equation 46 to substitute for $\mu$, their solution is now:

$$
\begin{aligned}
\mathrm{S} & =\mathrm{S}_{0} \mathrm{e}^{-\mathrm{kt}}, 0 \leqslant \mathrm{t}<\mathrm{T} \\
& =\theta \mathrm{S}_{0} \mathrm{e}^{-k \mathrm{~T}} /\left[\mathrm{S}_{0} \mathrm{e}^{-\mathrm{kT}}+\left(\theta-\mathrm{S}_{0} \mathrm{e}^{-\mathrm{kT}}\right) \mathrm{e}^{\mathrm{b} \theta(\mathrm{t}-\mathrm{T})}\right], \mathrm{t} \geqslant \mathrm{T},
\end{aligned}
$$

and

$$
\mathrm{U}=\mathrm{U}_{0} \mathrm{e}^{-\mathrm{kt}}, \mathrm{t} \geqslant 0,
$$

where $\theta$ denotes $\mathrm{K}+\mathrm{k} / \mathrm{b}$. The expressions for extent of ruminal degradation are equations 19 and 20 with:

$$
\mathrm{I}=\mathrm{bS}_{0}^{-1} \int_{\mathrm{T}}^{\infty}(\mathrm{K}-\mathrm{S}) \mathrm{Sdt} .
$$

On replacing $\mathrm{S}$ using equation $52 \mathrm{~b}$, this integral is nonanalytical and has to be evaluated numerically.

\section{Discussion}

In the present study, it was decided to construct different models of gas production based on the potentially degradable substrate (S) and its fractional degradation rate $(\mu)$. Not only does such a representation allow a proper comparison of the assumptions made in each model, but it also permits the extent of degradation in the rumen (E) (and hence microbial protein supply) to be calculated, thus providing an index of the nutritive value of feeds for animal production. Introducing further complexity into the representation by, for example, adding a microbial pool, would lead to either no analytical solution to the model or an overparameterized gas production equation. Most published models developed to analyse gas production profiles are based on the amount of gas produced rather than on the amount of substrate degraded, thus failing to link the gas production technique to animal performance (Krishnamoorthy et al. 1991; Beuvink \& Kogut, 1993; Blümmel \& Ørskov, 1993; Schofield et al. 1994; Groot et al. 1996).

The simple Mitscherlich function (equation 22) was among the first to be applied to cumulative gas production data (Krisnamoorthy et al. 1991; Blümmel \& Ørskov, 1993). This equation assumes that degradation occurs at a constant fractional rate $\mu$ after a discrete time lag $\mathrm{T}$. Thus, the rate of gas accumulation decreases continually and there is no point of inflexion. In applying the simple Mitscherlich, several research groups have included a parameter $\alpha$ denoting the immediately soluble material when applied to in sacco data, or the initial amount of gas produced when applied to gas production data (e.g. Blümmel \& Ørskov, 1993; Khazaal et al. 1993, 1994). Khazaal et al. (1993, 1994) frequently calculated negative values of $\alpha$, implying a negative initial gas volume. Yet initial gas volumes at the start of incubation should be zero, and in most experimental systems this is achieved by regulating the pressure in the incubation vessels before data are recorded. Thus, the gas production curve starts at zero volume, as in the present representation of the simple Mitscherlich (equation 22). Indeed, this representation of the simple Mitscherlich was applied by Krisnamoorthy et al. (1991, 1995).

Following automation of extant systems and development of new ones (Beuvink et al. 1992; Pell \& Schofield, 1993; Theodorou et al. 1994), it became apparent that cumulative gas production profiles varied in shape from steep diminishing returns to highly sigmoidal, and equation forms without a point of inflexion would no longer be appropriate in many cases. France et al. (1993) proposed a generalization of the Mitscherlich model (equation 10) to accommodate either sigmoidal or non-sigmoidal shapes. The fractional degradation rate $\mu$ can increase or decrease to an asymptote with this equation. This may reflect the increase in substrate accessibility due to hydration of particles, microbial attachment, and increase in microbial numbers after a lag time (McAllister et al. 1994). This generalization of the Mitscherlich model has been applied to gas production data from fermentation of roughages with mixed rumen micro-organisms or with single species (Theodorou et al. 1994, 1995; Williams et al. 1995, 1996; Sileshi et al. 1996). However, the assumption that $\mu$ approaches an asymptote is not unequivocal. Local build-up of fermentation endproducts, reduced availability of essential growth factors, and the imposition of chemical and structural restrictions, are all potential factors which could give rise to a reduced fractional degradation rate as degradation proceeds (Chesson, 1988; Wilson, 1993).

Schofield et al. (1994) proposed Gompertz and logistic equations to describe gas production data and compared these with exponential and simple Mitscherlich equations. Their derivations of the Gompertz and logistic equations differ from ours, as they start from the amount of gas produced. In their derivations, the amount of gas produced depends amongst other things on the amount of microbial biomass present. Microbial growth yield is assumed to be constant throughout incubation. Whilst microbial growth yield will be constant in steady-state situations and during the exponential phase in batch cultures (Pirt, 1975), this assumption is unlikely to be valid for the gas production 
technique. The Pirt (1975) double reciprocal equation relates efficiency to fractional growth rate of microorganisms and their non-growth requirements (maintenance), assuming that micro-organisms can utilize substrates for growth only when non-growth requirements have been satisfied. After the inflexion point, the rate of substrate degradation is reduced and microbial non-growth requirements form a larger part of the substrate utilized per unit time, reducing the fractional growth rate and consequently reducing microbial yield. Moreover, microbial growth yield will vary with such factors as microbial species present, $\mathrm{pH}$ of the medium, and availability of $\mathrm{N}$ substrates (Dijkstra \& France 1996), and these factors might change in the course of incubation. In our derivation of the Gompertz and logistic equations (equations 40 and 49 respectively), $\mu$ is assumed to increase with time. This increase can be interpreted as an increase in microbial activity per unit feed, but it does not involve any assumptions on the constancy of the microbial growth yield. Schofield et al. (1994) selected the logistic equation to describe gas production curves and applied this equation to describe them for several roughages and for the fibre and non-fibre fractions of roughages (Schofield \& Pell, 1995a,b). As with certain applications of the simple Mitscherlich model, an initial gas volume unavoidably arises with application of the Gompertz and logistic equations as given by Schofield et al. (1994), introducing an inherent error as gas volume at zero time should be nil. Note that our Gompertz equation is equivalent to the simple Mitscherlich equation when parameter $\mathrm{c}$ equals zero.

Groot et al. (1996) proposed a modified MichaelisMenten equation without formal derivation to describe gas production curves, and this equation has been applied by Cone et al. (1996). In our derivation of a generalized Michaelis-Menten (equation 27), the fractional degradation rate $\mu$ either decreases continuously $(c \leqslant 1)$, or increases first and decreases later during fermentation $(c>1)$. Again, an initial increase in $\mu$ reflects an increase in substrate accessibility due to hydration of particles, microbial attachment and increase in microbial numbers, whilst the decrease might reflect the imposition of chemical and structural restrictions. Thus, compared with our other gas production models, the assumptions concerning $\mu$ are more flexible.

The modified Michaelis-Menten equation has often been extended for multiphasic analysis, assuming that each single phase describes the gas produced by different components of the feedstuff. The number of phases included in a number of applications was two or three (Cone et al. 1996; Groot et al. 1996). Similarly, the logistic and Gompertz equations have been used multiphasically (Schofield et al. 1994; Schofield \& Pell, 1995a,b). In general, the robustness of an equation declined when the number of phases was increased, which is an inherent characteristic of these nonlinear models. In the present analysis only single-pool characterization of the potentially degradable fraction was considered. For multiple-pool characterization, total gas produced is obtained by simply summing over all the pools of degradable material, so the models derived in the present analysis can be used additively for multiphasic analysis without affecting the basic assumptions inherent in their derivations.
Not all gas production equations have been applied with a fixed lag phase before fermentation starts. Factors which affect the presence and length of a lag include the nature of the substrate incubated, the microbial species inoculated, and the amount of inoculum added (France et al. 1993; Pell \& Schofield, 1993; Cone et al. 1996). In fitting the present models the lag phase can simply be deleted from the equation if it does not significantly improve the fit of the curve, except in the case of the generalized Mitscherlich where a lag, albeit small, is needed to prevent a mathematical discontinuity in $\mu$ at zero time. There seems little to choose between the present models biologically and mathematically, so choice of best model should be made on the basis of fitting criteria (see Dhanoa et al. 2000).

\section{Acknowledgements}

Financial support for this project through a NATO Collaborative Research Grant (CRG 960240) is gratefully acknowledged. The research of J. Dijkstra has been made possible by a fellowship from the Royal Netherlands Academy of Arts and Sciences. The authors thank Dr B.A. Williams for her comments on the draft manuscript.

\section{References}

Beuvink JMW \& Kogut J (1993) Modeling gas production kinetics of grass silages incubated with buffered ruminal fluid. Journal of Animal Science 71, 1041-1046.

Beuvink JMW, Spoelstra SF \& Hogendorp RJ (1992) An automated method for measuring time-course of gas production of feedstuffs with buffered rumen fluid. Netherlands Journal of Agricultural Science 40, 401-407.

Blümmel M \& Ørskov ER (1993) Comparison of in vitro gas production and nylon-bag degradability of roughage in predicting feed intake in cattle. Animal Feed Science and Technology 40, 109-119.

Chesson A (1988) Lignin-polysaccharide complexes of the plant cell wall and their effect on microbial degradation in the rumen. Animal Feed Science and Technology 21, 219-228.

Cone JW, Van Gelder AH, Visscher GJW \& Oudshoorn L (1996) Influence of rumen fluid and substrate concentration on fermentation kinetics measured with a fully automated time related gas production apparatus. Animal Feed Science and Technology 61, 113-128.

Dhanoa MS, Lopez S, Dijkstra J, Davies DR, Sanderson R, Williams BA, Sileshi Z \& France J (2000) Estimating the extent of degradation of ruminant feeds from a description of their gas production profiles observed in vitro: comparison of models. British Journal of Nutrition, 83, 131-142.

Dijkstra J \& France J (1996) A comparative evaluation of models of whole rumen function. Annales de Zootechnie 45, 175-192.

France J, Dhanoa MS, Theodorou MK, Lister SJ, Davies DR \& Isac D (1993) A model to interpret gas accumulation profiles associated with in vitro degradation of ruminant feeds. Journal of Theoretical Biology 163, 99-111.

France J, Dijkstra J, Thornley JHM \& Dhanoa MS (1996) A simple but flexible growth function. Growth, Development and Aging 60, 71-83.

Groot JCJ, Cone JW, Williams BA, Debersaques FMA \& Lantinga EA (1996) Multiphasic analysis of gas production kinetics for in vitro fermentation of ruminant feeds. Animal Feed Science and Technology 64, 77-89.

Khazaal K, Dentinho MT, Ribeiro JM \& Ørskov ER (1993) A 
comparison of gas production during incubation with rumen contents in vitro and nylon bag degradability as predictors of the apparent digestibility in vivo and the voluntary intake of hays. Animal Production 57, 105-112.

Khazaal K, Boza J \& Ørskov ER (1994) Assessment of phenolicsrelated antinutritive effects in Mediterranean browse: a comparison between the use of the in vitro gas production technique with or without insoluble polyvinylpolypyrrolidone or nylon bag. Animal Feed Science and Technology 49, 133-149.

Krishnamoorthy U, Soller H, Steingass H \& Menke KH (1991) A comparative study on rumen fermentation of energy supplements in vitro. Journal of Animal Physiology and Animal Nutrition 65, 28-35.

Krishnamoorthy U, Soller H, Steingass H \& Menke KH (1995) Energy and protein evaluation of tropical feedstuffs for whole tract and ruminal digestion by chemical analyses and rumen inoculum studies in vitro. Animal Feed Science and Technology 52, 177-188.

McAllister TA, Bae HD, Jones GA \& Cheng K-J (1994) Microbial attachment and feed digestion in the rumen. Journal of Animal Science 72, 3004-3018.

Merry RJ, Theodorou MK, Raurich MG \& Dhanoa MS (1991) Use of head-space gas pressure in batch cultures to assist in determination of nutritive value of silage to rumen bacteria. In Forage Conservation 2000, pp. 451-454 [G Pahlow and $\mathrm{H}$ Honig, editors]. Braunschweig, Germany: Institute of Grassland and Forage Research, Federal Research Center of Agriculture, Braunschweig-Volkenrode (FAL).

Ørskov ER \& McDonald I (1979) The estimation of protein degradability in the rumen from incubation measurements weighted according to rates of passage. Journal of Agricultural Science, Cambridge 92, 499-503.

Pell AN \& Schofield P (1993) Computerized monitoring of gas production to measure forage digestion in vitro. Journal of Dairy Science 76, 1063-1073.

Pirt SJ (1975) Principles of Microbe and Cell Cultivation. Oxford: Blackwell Scientific Publications.
Schofield P \& Pell AN (1995a) Validity of using accumulated gas pressure readings to measure forage digestion in vitro: a comparison involving three forages. Journal of Dairy Science 78, 2230-2238.

Schofield P \& Pell AN (1995b) Measurement and kinetic analysis of the neutral detergent soluble carbohydrate fraction of legumes and grasses. Journal of Animal Science 73, 3455-3463.

Schofield P, Pitt RE \& Pell AN (1994) Kinetics of fibre digestion from in vitro gas production. Journal of Animal Science $\mathbf{7 2}$, 2980-2991.

Sileshi Z, Owen E, Dhanoa MS \& Theodorou MK (1996) Prediction of in situ rumen dry matter disappearance of Ethiopian forages from an in vitro gas production technique using a pressure transducer, chemical analyses or in vitro digestibility. Animal Feed Science and Technology 61, 73-87.

Theodorou MK, Davies DR, Nielsen BB, Lawrence MIG \& Trinci APJ (1995) Determination of growth of anaerobic fungi on soluble and cellulosic substrates using a pressure transducer. Microbiology 141, 671-678.

Theodorou MK, Williams BA, Dhanoa MS, McAllan AB \& France J (1994) A simple gas production method using a pressure transducer to determine the fermentation kinetics of ruminant feedstuffs. Animal Feed Science and Technology 48, 185-197.

Williams BA, Chuzaemi C, Soebarinoto, Van Bruchem J, Boer H \& Tamminga $S$ (1996) A comparison of ten rice-straw varieties grown at two different altitudes during a wet and a dry season, using the in vitro cumulative gas production technique. Animal Feed Science and Technology 57, 183-194.

Williams BA, Van der Poel AFB, Boer H \& Tamminga S (1995) The use of cumulative gas production to determine the effect of steam explosion on the fermentability of two substrates with different cell wall quality. Journal of the Science of Food and Agriculture 69, 33-39.

Wilson JR (1993) Organization of forage plant tissues. In Forage Cell Wall Structure and Digestibility, pp. 1-32 [HG Jung, DR Buxton, RD Hatfield and J Ralph, editors]. Madison, WI: American Society of Agronomy. 